\title{
Low resistance polycrystalline diamond thin films deposited by hot filament chemical vapour deposition
}

\author{
MAHTAB ULLAH, EJAZ AHMED, ABDELBARY ELHISSI ${ }^{\dagger}$ and WAQAR AHMED ${ }^{\dagger, *}$ \\ Department of Physics, Bahauddin Zakariya University, Multan, Pakistan \\ ${ }^{\dagger}$ Institute of Nanotechnology and Bioengineering, University of Central Lancashire, Preston PR1 2HE, \\ United Kingdom
}

MS received 7 November 2012; revised 9 May 2013

\begin{abstract}
Polycrystalline diamond thin films with outgrowing diamond (OGD) grains were deposited onto silicon wafers using a hydrocarbon gas $\left(\mathrm{CH}_{4}\right)$ highly diluted with $\mathrm{H}_{2}$ at low pressure in a hot filament chemical vapour deposition (HFCVD) reactor with a range of gas flow rates. X-ray diffraction (XRD) and SEM showed polycrystalline diamond structure with a random orientation. Polycrystalline diamond films with various textures were grown and (111) facets were dominant with sharp grain boundaries. Outgrowth was observed in flowerish character at high gas flow rates. Isolated single crystals with little openings appeared at various stages at low gas flow rates. Thus, changing gas flow rates had a beneficial influence on the grain size, growth rate and electrical resistivity. CVD diamond films gave an excellent performance for medium film thickness with relatively low electrical resistivity and making them potentially useful in many industrial applications.
\end{abstract}

Keywords. Carbon materials; chemical vapour deposition; crystal growth; thin films; electrical resistivity; grain size.

\section{Introduction}

Diamond has a wide range of applications in fields such as mechanics, electronics and optics due to its classic film properties such as high thermal conductivity, wide bandgap, best mechanical hardness and chemical inertness (Davis 1992; Kobayashi et al 1999). The utilization of diamond as an insulating material in electronic devices (Okumura et al 2010) requires the low electrical resistivity for diamond films used as cooling materials in such devices. For semiconductor applications low resistivity, smooth and good quality diamond films with nanograins are highly desirable. Considerable research has been conducted to increase the growth rate of diamond by varying many parameters such as deposition pressure, gas flow rate, substrate temperature, etc. Rau and Picht (1992) showed that the mass transport in the gas phase plays an important role during diamond growth. Nucleation and growth of diamond films can be controlled by the mass transport rate rather than the surface reaction rate at high substrate temperatures. In the past decade, various research reported different results by varying gas flow rates in the deposition chamber. For instance, Fan et al (1999) reported no effect of gas flow on the growth rate.

\footnotetext{
*Author for correspondence (prof.w.ahmed@gmail.com; wahmed4@uclan.ac.uk)
}

In another study, Yu et al (1998) have demonstrated that growth rate increases by increasing the gas flow rate whilst Celii et al (1991) reported that the gas flow had little effect on the growth rate. Thus, in order to depict the effects caused by various gas flow rates in the deposition chamber more research is needed. This research was carried out to understand the changes caused by methane concentration on the growth rate of diamond.

In this study, diamond growth on (100) silicon substrates has been investigated at various methane concentrations whilst keeping all other parameters constant to investigate the electrical resistivity for diamond film utilization in cooling devices or as semiconductors (Okumura et al 2010). Films deposited have been analysed using scanning electron microscopy (SEM), X-ray diffraction and Raman spectroscopy. The relationship between the diamond film growth rate and methane concentration decreases the resistivity at various methane concentrations has been investigated and evaluated.

\section{Experimental}

Microcrystalline diamond films were deposited onto silicon (Si) substrate using HFCVD. Circular Si (100) wafers $(\phi=10 \mathrm{~cm})$ with smooth and plane surface were used as substrates, prior to deposition, the wafers were ultrasonically cleaned in ethanol, deionized water and hydrofluoric 
acid (HF) to remove the oxide layer. Silicon substrates on $8 \mathrm{~cm}$ molybdenum holder were placed into the reaction chamber. Hydrogen and $1 \%$ methane in $\mathrm{N}_{2}$ were introduced simultaneously into the reaction chamber at various flow rates $(0.2 / 2 ; 0.3 / 3 ; 0.4 / 4$ and $0.5 / 5$ each measured in $\mathrm{mL} / \mathrm{min})$. The pressure in the chamber was maintained at 30 mbar. The source gases $\left(\mathrm{CH}_{4}+\mathrm{H}_{2}\right)$ were thermally activated by $0.5 \mathrm{~mm}$ thick eight co-planar tungsten filaments separated by $5 \mathrm{~mm}$ spacing. Gas flow rates were controlled by using a precision mass flow controller. Deposition time was about $20 \mathrm{~h}$. Temperature of filament and substrate were $\sim 2800{ }^{\circ} \mathrm{C}$ and $900{ }^{\circ} \mathrm{C}$, respectively, measured by thermocouples placed close to them. Asgrown films were examined using SEM (LEO 1550 with acceleration voltage of $10 \mathrm{kV}$ ), X-ray diffraction spectroscopy (D500, $\mathrm{CuK} \alpha, \lambda=0.1541 \mathrm{~nm}$ ) and Raman spectroscopy with visible excitation (Filik 2005) at room temperature. Raman spectra were analysed with a backscattering geometry using $514 \mathrm{~nm}$ lines of an $\mathrm{Ar}^{+}$laser. Spectra were collected using Renishaw 2000 microRaman system. A laser output of $10 \mathrm{~mW}$ was used and the laser spot was focused on the sample surface using a $20 \times$ objective with short-focus working distance. The resistivity was investigated using a 4-point probe current/voltage in van der Pauw (1958) geometry at room temperature with maximum voltage of $\pm 100 \mathrm{~V}$. The current and voltage were measured using a semiconductor device analyser (Agilent B1500A).

\section{Results and discussion}

To investigate the effect of varying gas concentration on the structure of diamond thin films, X-ray diffraction

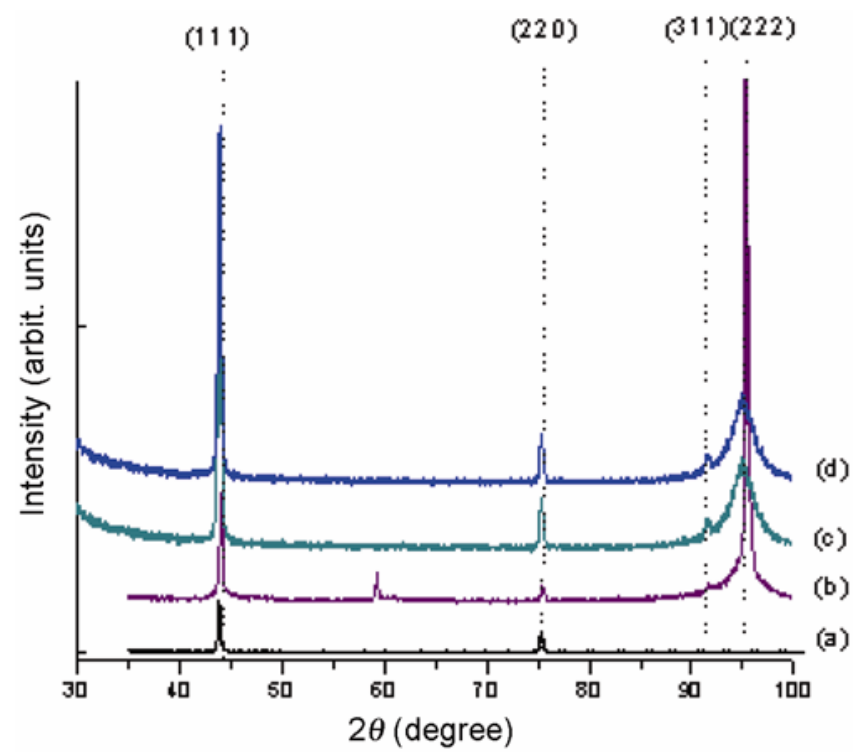

Figure 1. XRD patterns of four diamond films with various methane concentrations $(\mathrm{mL} / \mathrm{min})$ : (a) $2 \cdot 0$, (b) $3 \cdot 0$, (c) $4 \cdot 0$ and (d) $5 \cdot 0$.
(XRD) analysis was carried out. Figure 1 shows representative spectra of diamond thin films with a typical diamond (cubic) structure. The characteristic $\{111\},\{220\}$, $\{311\}$ and $\{222\}$ peaks of diamond structure were clearly visible at $2 \theta$ values of $43,75,91$ and $95^{\circ}$. Few weak silicon (carbide) peaks [JCPDS Card No 77-2111 (Si), 741302 (SiC)] were also present, since silicon being used as the substrate material for the deposition of diamond thin films. FWHM of the diamond $\{111\}$ (or $\{222\}$ ) XRD peak observed at $2 \theta$ angles of $\sim 43^{\circ}$ (or $\sim 95^{\circ}$ ) is a qualitative measure of the degree of crystallinity within the diamond deposit. The FWHM is dependent on both the grain size and crystallinity with a tendency to become narrower when the grain size is larger. A comparison of the $\{111\}$ diamond peak for a series of depositions at a range of gas concentrations revealed an increase in peak intensity (figure 1). Higher gas concentrations led to a considerable variation in the intensity of all $\{111\}$, $\{220\},\{311\}$ and $\{222\}$ signals. FWHM of XRD $\{111\}$ peak clearly demonstrates the improvements in the grain size of the diamond polycrystals with the gas concentration whilst higher concentrations leads to degradation in grain size due to high nucleation rate with some outgrowth ( $\{222\}$ peak in figure 1$)$. These findings are consistent with both SEM and Raman results. This morphological trend is in agreement with those previously reported (Huang et al 1997; Chen et al 2006). From these experimental findings, it can be concluded that gas concentration has to be optimized in order to improve the quality of diamond crystals.

In SEM micrographs (figures 2c and d) some outgrowth was observed, which can be related with the carbon conversion efficiency. It is calculated mathematically using a formula explained by Bataineh et al (2005):

$$
\begin{aligned}
& \text { Carbon supplied (atoms } / \mathrm{h}) \\
& \quad=D(\mathrm{cc} / \mathrm{mm}) \times\left(60(\mathrm{~mm} / \mathrm{h}) \times\left(6.024 \times 10^{23}(\text { atoms }) /\right.\right. \\
& 22400(\mathrm{cc}))=1.6136 \times 10^{21} D(\text { gas phase }), \\
& \text { Carbon added to the film }(\text { atoms } / \mathrm{h}) \\
& \quad=C(\mathrm{~g} / \mathrm{h}) \times\left(1\left(\mathrm{~cm}^{3}\right) / 3.515(\mathrm{~g})\right) \times\left(1.79 \times 10^{23}(\text { atoms }) /\right. \\
& \left.1\left(\mathrm{~cm}^{3}\right)\right)=5 \cdot 0925 \times 10^{22} C(\text { solid phase }), \\
& \% \text { Carbon conversion efficiency } \\
& =(\text { carbon added to the film/carbon supplied by gas }) \\
& \quad \times 100=3156(C / D) \%,
\end{aligned}
$$

where $C(\mathrm{~g} / \mathrm{h})$ is the amount of carbon added to the film and $D(\mathrm{sccm})$ is the carbon supplied by input gas. At high methane concentration, the conversion efficiency from carbon to diamond is noted to increase for a moment and then becomes normal. The behaviour of carbon conversion efficiency for present polycrystalline films is comparable to that of Bataineh et al (2005).

SEM micrographs (figure 2) showed that increasing the gas flow rate, the film surface morphology gradually changed from small grain size to enhanced growth/grain 

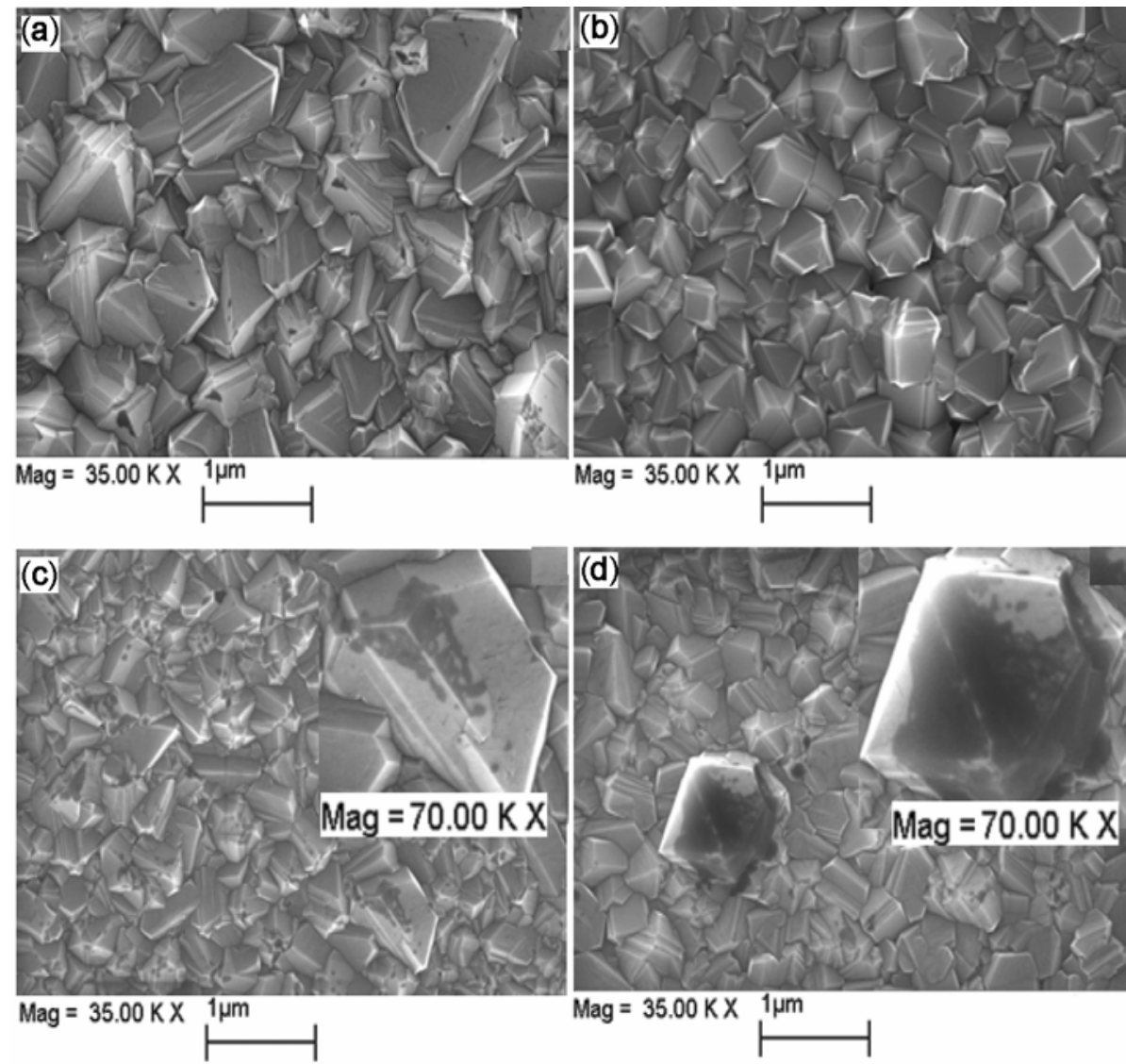

Figure 2. SEM micrographs of four diamond samples at various methane concentrations $(\mathrm{mL} / \mathrm{min}):$ (a) $2 \cdot 0$, (b) $3 \cdot 0$, (c) $4 \cdot 0$, (d) $5 \cdot 0$; insets in figures (d) and (e) are their corresponding SEM images at $70 \mathrm{kX}$ magnifications.

size. At low methane concentration $(2 \mathrm{~mL} / \mathrm{min})$, highly oriented and well-faceted micro-crystalline diamond (MCD) films with an average grain size of $2.5 \mu \mathrm{m}$ were deposited (figure 2(a)). Increasing the methane concentration to $3 \mathrm{~mL} / \mathrm{min}$ the grain size decreased to $1.3 \mu \mathrm{m}$ with well-faceted grain orientations (figure 2(b)). Further increase in the methane content from 4 to $5 \mathrm{~mL} / \mathrm{min}$ (figure $2(\mathrm{c}, \mathrm{d}))$ resulted in overgrowth of the diamond grains $(2.9 \mu \mathrm{m})$ with some amorphous spots. This indicates the prevailing effects of gas flow rate on the diamond growth rate especially at higher methane concentrations. This diamond growth behaviour in contrast with that was observed by Yu et al (1997). This is attributed to the conversion efficiency at high methane contents, as explained by Bataineh and co-workers (2005).

Micro-Raman spectroscopy in the wavenumber range $100-2000 \mathrm{~cm}^{-1}$ was used to compare the quality of diamond crystals grown at different methane concentrations. At low methane concentration, a sharp peak at $1332 \mathrm{~cm}^{-1}$ is linked to natural diamond was observed (figure 3). At high concentration of methane, this peak shifted to $1335 \mathrm{~cm}^{-1}$ is due to compressive stress. Local outgrowth in the diamond crystals increased simultaneously with increasing methane concentration at a pressure of $\sim 30$ mbar (figures 3(c, d)). This outgrowth in local diamond rises the internal stress and is responsible for decreasing diamond quality as calculated by (1), which can be minimized by optimizing the methane concentration. Shifting in the diamond peak and outgrowth have also been observed by Schwarz et al (2002) at pressure values of 3 and 50 mbar. Another peak around $1530 \mathrm{~cm}^{-1}$ ( $\mathrm{G}$ band) originating from disordered and glassy amorphous carbon in the vicinity of grains did not appear at low methane concentration, but appeared at high methane concentration. The peak observed at $1123 \mathrm{~cm}^{-1}$ is due to amorphous networks/nanocrystalline diamond (Schwarz et al 2002). Two extra peaks at around 525 and $604 \mathrm{~cm}^{-1}$ were induced due to local disorder (Buckley et al 1989) at low methane concentration and disappeared at high concentration (figure 3). Moreover, FWHM of diamond peak at $1332 / 1335 \mathrm{~cm}^{-1}$ increased with increasing methane concentration. The area under peak increased with increasing methane concentration as reported earlier by many investigators (Wada and Olin 1981; Shroder et al 1990; Goodwin 1993; Silva et al 1996). 


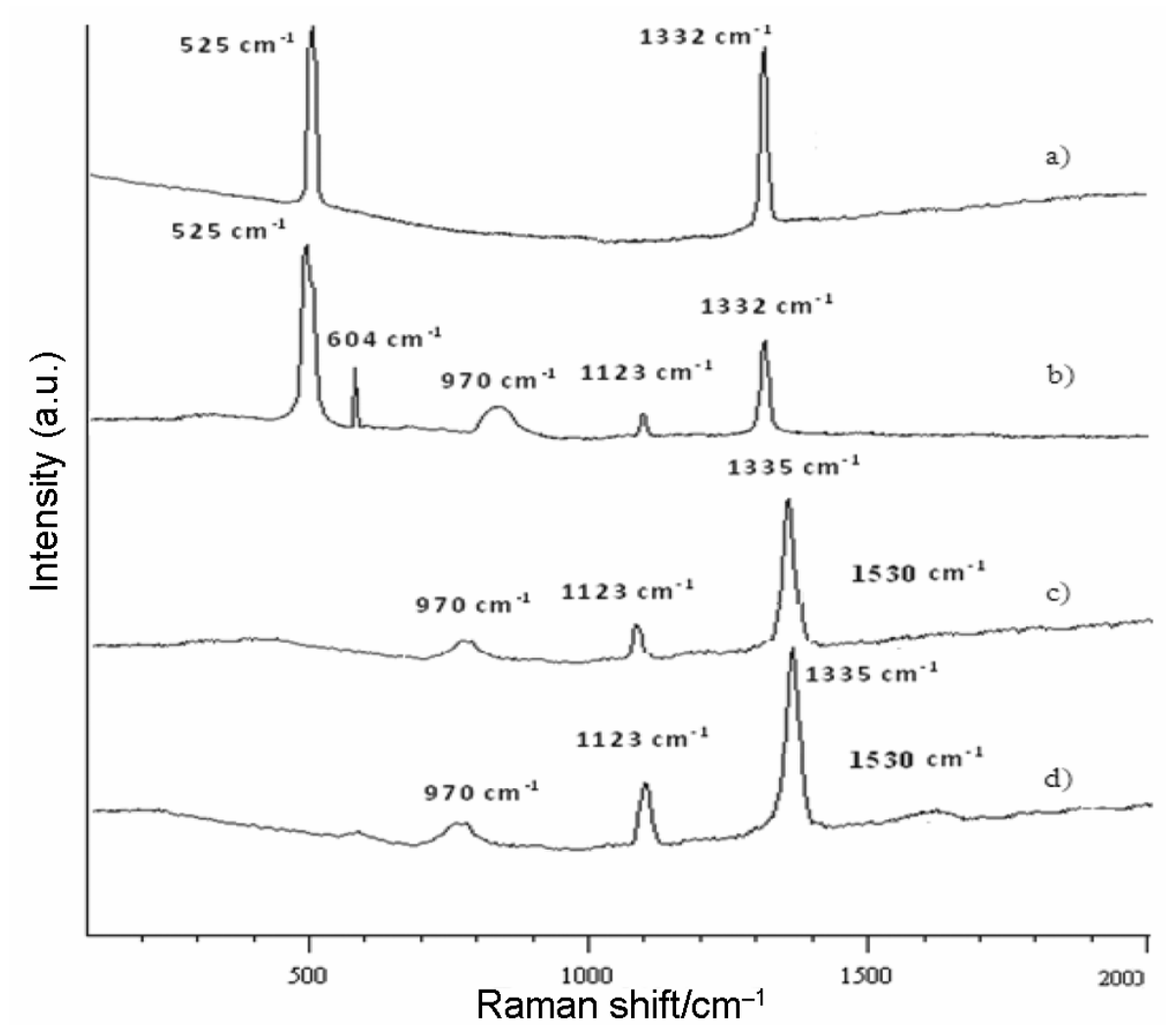

Figure 3. Raman spectra of four diamond films at various methane concentrations (mL/min): (a) $2 \cdot 0$, (b) $3 \cdot 0$, (c) $4 \cdot 0$ and (d) $5 \cdot 0$.

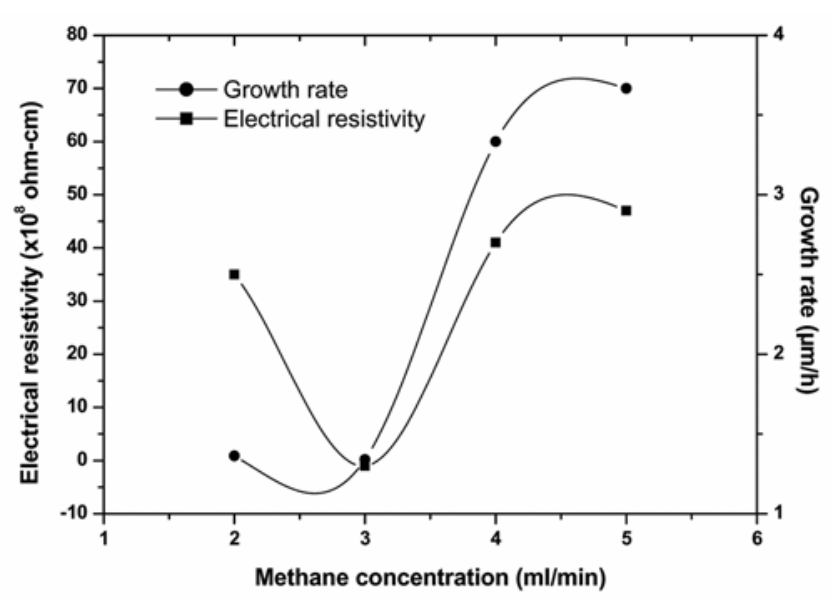

Figure 4. Electrical resistivity (left) and growth rate (right) as a function of methane concentration.

Effect of methane concentration on diamond growth rate as determined from different cross-sectional SEM measurements was observed in figure 4 , which indicates a general increase with rise of methane concentration. Diamond growth rate increased as a result of increasing the amount of atomic hydrogen and diamond precursors on the substrate. Similar results were observed by other investigators Ralchenko et al 1999; Hirakuri et al 2001; Li et al 2006; Lu et al 2007). Electrical resistivity (figure 4) was low at lower methane concentration but increased at higher methane concentrations. Lower resistivity may be due to the rise of $s p^{2} / s p^{3}$ ratio at low methane concentration (Ma et al 2006) as observed in Raman spectra (figure $3)$. The electrical resistivity was the lowest $(1.79 \times$ $10^{7} \mathrm{ohm}-\mathrm{cm}$ ) when methane concentration was $3.0 \mathrm{~mL} /$ min (figure 3 ). The increase in resistivity at high methane concentrations is attributed to the outgrowth of local diamond and clustering of similar atoms since short range ordering causes the electrical resistivity to decrease while clustering can increase the resistivity (Chen et al 2004; Abbas et al 2007).

\section{Conclusions}

The diamond growth rate was directly related to the methane concentration. A decrease in the growth rate was observed at low methane concentrations and an increase at high methane concentrations by a factor of about 3 . The quality of diamond crystals improved at low methane concentration and gradually degraded by increasing the methane concentration. The optimum methane concentration for well faceted diamond was found to be $3.0 \mathrm{~mL} / \mathrm{min}$. Outgrowth was observed when excess methane was added 
to the deposition chamber. Electrical resistivity generally increased with increasing the methane concentration, having a minimal value $\left(1.79 \times 10^{7} \mathrm{ohm}-\mathrm{cm}\right)$ at methane concentration of $3.0 \mathrm{~mL} / \mathrm{min}$. Low resistance and good quality diamond films can be used in semiconductor devices whilst high resistivity polycrystalline diamond films find their applications as cooling materials.

\section{Acknowledgement}

This work was supported by Higher Education Commission (HEC) of Pakistan, under International Research Support Initiative Program (IRSIP).

\section{References}

Abbas T, Ullah M, Rana A M and Arif Khalil R M 2007 Mater. Sci. Poland 251161

Bataineh M, Khatami S and Asmussen Jr J 2005 J. Mater. Process Technol. 16926

Buckley G, Moustakas T D, Ye L and Voiron J $1989 \mathrm{~J}$. Appl. Phys. 663595

Celii F G, White D Jr and Purdes A J 1991 J. Appl Phys. 705636

Chen X, Sullivan J, Friedmann T and Murray Gibson J 2004 Microsci. Microanal. 10 (Suppl 2)

Chen W, Lu X, Yang Q, Xiao C, Sammynaiken R and Maley J 2006 Thin Solid Films 5151970

Davis R F 1992 Diamond films and coatings (New Jersey: Noyes Publications) p. 381
Fan Q H, Pereira E and Cracio J 1999 J. Mater. Sci. 34 1353

Filik J 2005 Spectro. Euro. 1710

Goodwin D G 1993 J. Appl. Phys. 746888

Hirakuri K K, Kobayashi T, Nakamura E, Mutsukura N, Friedbacher G and Machi Y 2001 Vacuum 63449

Huang J Yu, Wen R and Shi L C 1997 Mater. Lett. 32143

Kobayashi T, Hirakuri K K, Mutsukura N and Machi M 1999 Diamond Relat. Mater. 81057

Li X, Perkin J, Collazo R, Nimanich R J and Sitar Z 2006 Diamond Relat. Mater. 151784

Lu X, Yang Q, Xiao C and Hirose A 2007 Diamond Relat. Mater. 161623

Ma K L, Zhang W J, Zou Y S, Chong Y M, Leung K L, Bello I and Lee S T 2006 Diamond Relat Mater. 15626

Okumura Y, Kanayama K and Shogaki K-I 2010 Combust. Flame 1571052

Ralchenko V, Sychov I, Vlasov I, Valsov A, Konov V, Khomich A and Voronina S 1999 Diamond Relat. Mater. 8 189

Rau H and Picht F 1992 J. Mater. Res. 7934

Schwarz S, Rosiwal S M, Frank M, Breidt D and Singer R F 2002 Diamond Relat. Mater. 11589

Shroder R E, Nemanich R J and Glass J T 1990 Phys. Rev. B41 3738

Silva Gicquel F A, Tardieu A, Cledat P and Chauveau T 1996 Diamond Relat. Mater. 5338

Van der Pauw L J 1958 Philips Res. Rep. 131

Wada N and Olin S A S 1981 Physica B 105353

Yu J, Huang R, Wen L and Shi C 1998 J. Mater. Sci. Lett. 17 1011 